\title{
Substituent Influence on the Diastereoselectivity of the Alkylation of Cyclic Chiral Imines
}

\author{
Éverton M. dos Santos, ${ }^{a}$ Marizane Bogdan, ${ }^{a}$ Maurício M. Victor, ${ }^{b}$ Beatriz S.M. Tenius $^{a}$ and \\ Eduardo R. de Oliveira ${ }^{*, a}$
}

\author{
${ }^{a}$ Instituto de Química, Universidade Federal do Rio Grande do Sul, CP 15003, 91501-970 Porto Alegre-RS, Brazil \\ ${ }^{b}$ Instituto de Química, Universidade Federal da Bahia, Campus de Ondina, 40170-290 Salvador-BA, Brazil
}

\begin{abstract}
A alta diastereosseletividade, normalmente observada na reação de alquilação de iminas quirais derivadas de cetonas cíclicas, não é observada no caso de cetonas com substituintes quirais. A influência do tamanho do substituinte foi estudada com iminas preparadas a partir da $(5 R)$-2,5-dimetilciclohexanona e $(5 R)$-carvomentona com ambos enantiômeros da 1-feniletilamina (PEA). Usando metil vinil cetona como eletrófilo, um caso matched foi observado com a imina derivada da (S)-PEA. Entretanto, o ed depende fortemente do substituinte no caso mismatched partindo-se da $(R)$-PEA. O aumento do volume do substituinte leva à diminuição do $e d$ na ordem ${ }^{i} \mathrm{Pr}-<\mathrm{CH}_{2}=\mathrm{C}\left(\mathrm{CH}_{3}\right)-<\mathrm{Me}-$. Os resultados são explicados pela hipótese de um controle estereoeletrônico a favor de um ataque axial ao tautômero enamina. $\mathrm{O}$ equilíbrio conformacional da enamina aparenta ser crucial para explicar os dados experimentais. No caso matched somente um confôrmero é esperado enquanto a mistura dos confôrmeros é postulada no caso mismatched.
\end{abstract}

The normal very high diastereoselectivity of alkylation reaction of chiral imines derived from cyclic ketones is not observed in the case of substituted chiral ketones. The influence of the substituent size was studied for imines prepared from $(5 R)$-2,5-dimethylcyclohexanone and $(5 R)$-carvomenthone with both enantiomers of 1-phenylethylamine (PEA). Using methyl vinyl ketone as electrophile a matched situation was observed with $(S)$-PEA imine derivative. However, the $d e$ is strongly dependent of the substituent in the mismatched case, starting from $(R)$-PEA. Enlargement of substituent size leads to lowering de in the order ${ }^{i} \mathrm{Pr}-<\mathrm{CH}_{2}=\mathrm{C}\left(\mathrm{CH}_{3}\right)-<\mathrm{Me}-$. The results are reasoned by the assumption of a stereoelectronic control in favour of an axial attack at enamine tautomer. The conformational equilibrium of enamine seems to be crucial to explain experimental data. In matched case only one conformer is expected while a mixture of conformers is postulated in the mismatched one.

Keywords: chiral imines, Michael reaction, diastereoselectivity

\section{Introduction}

The Michael addition using chiral imines derived from racemic ketones, developed by d'Angelo and co-workers ${ }^{1}$ constitutes a very important tool for the construction of a $\alpha$ carbonyl quaternary asymmetric center. This reaction, highly diastereo- and regioselective, was reviewed by d'Angelo's group on its mechanistic trends ${ }^{2}$ and synthetic applications. ${ }^{3}$

The regioselectivity of alkylation of 2 -substituted cyclohexanones, on their imine derivatives, normally very high in favour of 2,2-disubstituted product, decreases using very reactive electrophiles as nitroalkenes ${ }^{4}$ or 1,1 bis(phenylsulfonyl)ethylene. ${ }^{5}$ More troublesome is the

*e-mail: eroliv@iq.ufrgs.br lack of regioselectivity with "normal" electrophiles as vinyl ketones ${ }^{6}$ or acrylates ${ }^{7}$ when a resident chiral center is present in the imine cycle. These unexpected results could reveal the influence of conformational factors in the enamine cycle during the transition state of addition step. These conformational factors must be considered also in the analysis of the alkylation of imines derived from $(7 R)$-dihydrocarvone. ${ }^{8}$ We observed a matched situation in the alkylation of the imine obtained from $(S)$ 1-phenylethylamine $(S)$-(PEA) (1) using methyl vinyl ketone (MVK) as electrophile ( $d e>95 \%)$. However, the alkylation of imine prepared from $(R)$-PEA $(\mathbf{1})$ in the same conditions presents a low diastereoselectivity $(d e=58 \%)$, a mismatched situation. Revial ${ }^{9}$ in a pioneering work and Witschel and Bestmann ${ }^{10}$ have described the alkylation 
of imines bearing resident chiral centers but only matched results are described.

Despite its moderate diastereoselectivity, our methodology, seems to be a very good improvement to earlier procedures. ${ }^{11}$ Using this methodology, we were able to prepare the natural (+)- $\alpha$-cyperone..$^{12} \mathrm{Li}$ and coworkers ${ }^{13}$ synthesized the same molecule and some derivatives as well other natural products like (+)eudesma-3,11(13)-dien-12-oic acid, ${ }^{14}(-)-13$-hydroxy- $\alpha$ eudesmol ${ }^{15}$ and others. ${ }^{16}$ Finally, allohedycaryol was prepared by de Groot. ${ }^{17}$

The main features of the mechanism of Michael reaction were pointed out by d'Angelo et al. ${ }^{2}$ Based on the computational work of Sevin et al. ${ }^{18}$ and several experimental data it was postulated a compact transition state with concerted internal hydrogen transfer leading to high regio and stereoselectivity. ${ }^{2}$ Early an empirical model was designed accounting to the stereoselection of alkylation. The more substituted enamines, obtained from both enantiomers of PEA (1), approach the electrophile by the less hindered face, yielding the corresponding adducts in a diastereoselective process. It is noteworthy the ability of the empirical model to describe the results when the enamine cycle is not substituted, but it cannot explain the mismatched results. In a more detailed work, Sevin et al. ${ }^{19}$ showed the importance to consider the hybridization of nitrogen atom in the conformation of enamines. Excepting vinylamine, the standard geometry of nitrogen atom is pyramidal, so the use of an enamine planar model could not represent the true structure, making difficult the statement of a theoretical model to explain the stereochemical course of the reaction.

More recently, Tran-Huu-Dau et al. ${ }^{20}$ studying structures like enaminone 2 demonstrated the previous considerations of an anti attack with respect to the phenyl group, as shown in Figure 1. The results are supported by crystallographic data of enaminoesters, ${ }^{21}$ in which the conformation around $\mathrm{C}^{*}-\mathrm{N}$ bond is nearly the same obtained in a $R e$ approach to enaminone 2 . The calculations are simplified because in an extended conjugated system the nitrogen atom assumes a planar geometry and the cyclopentene ring is not so flexible as a cyclohexene one.
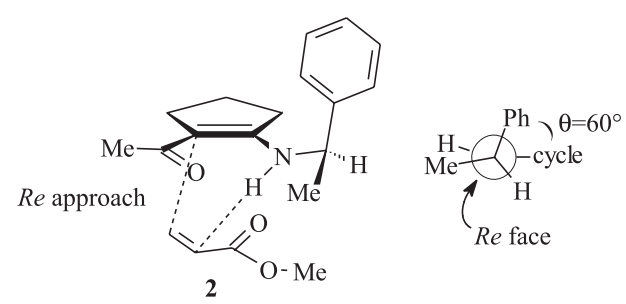

Figure 1.
Another postulate for the origin of diastereoselectivity was proposed by Lucero and Houk in 1997.22 The authors using ab-initio methods, estimated in $2.0 \mathrm{kcal} \mathrm{mol}^{-1}$ the difference of activation energy between axial and equatorial attacks in the $\mathrm{N}$-methylaminocyclohexene (3), in agreement with known stereoelectronic preference for the alkylation of enolates and enolethers. ${ }^{23}$ By MMX calculations, they estimated in $0.8 \mathrm{kcal} \mathrm{mol}^{-1}$ the difference of heat of formation of two limiting conformers of enaminoester $\mathbf{4}$, favouring $\mathbf{4}^{\prime}$ in which there were less severe non-ligand interactions between the allylic hydrogens and the substituents of chiral ligand ${ }^{22}$ as shown in Figure 2.
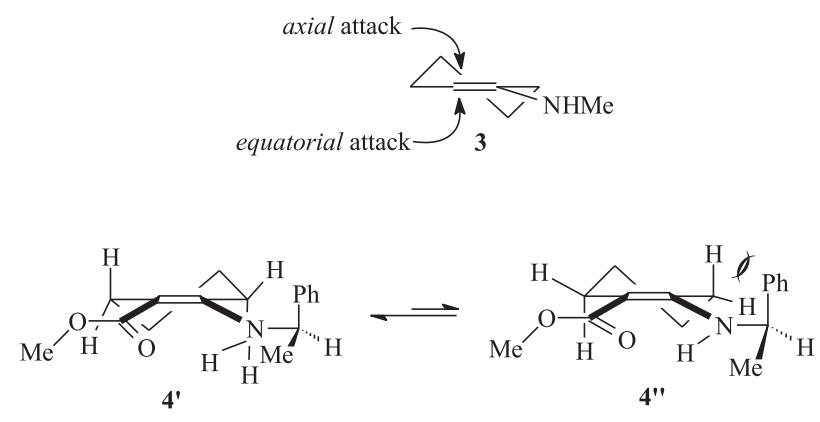

Figure 2.

By Houk's reasoning, ${ }^{22}$ the preferential attack becomes an axial Re attack in the more stable conformer 4', in accordance with experimental results. ${ }^{2}$ The advantage of this new model is the assumption of conformational effects in enamine ring, and the stereoelectronic effects to determine the diastereoselectivity.

The presence of resident substituents in the cycle can strongly direct the equilibrium position of $\mathbf{4}$ analogs, then affecting both regio and stereoselectivity ${ }^{8}$ of Michael addition. ${ }^{24}$

So, we decided to investigate the stereochemical course of the Michael alkylation of chiral imines $\mathbf{6}$ and $\mathbf{7}$ with variable size resident substituents in chiral centers, allowing the verification of the influence of conformational equilibrium in enamine cycle on the diastereoselectivity of alkylation reaction.

\section{Results and Discussion}

The acid-catalyzed retro-aldol reaction of $(R)$-pulegone (10) $\left(\mathrm{HCl}_{\text {aq }}\right.$, reflux, 8h), using standard conditions ${ }^{25}$ leads to $70 \%$ of $(R)-3$-methylcyclohexanone (11), obtained without loss of optical activity. Several attempts to optimize the regioselective alkylation of $\mathbf{1 1}$ were made but in spite of variable conditions studied the 
regioselectivity was poor. The best results coming from aprotic conditions ( 2 equiv. LDA, THF) in the presence of 5 equiv. $\mathrm{LiBr},{ }^{26}$ leading to a mixture of regioisomers $\mathbf{5 a}$ and 12 in $4: 1$ ratio with $85 \%$ yield. Similar results were pointed out in a recent work. ${ }^{27}$ The regioisomers, inseparable by chromatography even via its semicarbazone derivatives, ${ }^{28}$ were used combined in the next step.

Direct hydrogenation of $(R)$-carvone $(\mathbf{1 3})$ despite its apparent simplicity becomes troublesome. The use of standard hydrogenation conditions ${ }^{29}\left(1 \mathrm{~atm}_{2}, 10 \% \mathrm{Pd} /\right.$ C) in our hands yields only the aromatic by-product carvacrol (14), without detection of expected carvomenthone (5b). Catalytic transfer hydrogenation, using cyclohexene as hydrogen donor ${ }^{30}$ leads to no reaction and using limonene ${ }^{31}$ only $\mathbf{1 4}$ was also obtained. This problem was circumvented by the conversion of $\mathbf{1 3}$ into $(5 R)$-dihydrocarvone. ${ }^{8}$ So the hydrogenation could be performed, but moderate pressure was required (15 atm $\left.\mathrm{H}_{2}, 10 \% \mathrm{Pd} / \mathrm{C}\right)$ to obtain a good yield of the desired $(5 R)$ carvomenthone (5b). It was prepared in $85 \%$ from carvone (13).

Imines 6 and 7 were prepared in a conventional procedure $^{8}((S)$ or $(R)$-PEA $(\mathbf{1}), p$-TSA, benzene with azeotropic removal of water) in yields from $81 \%$ to $87 \%$ all of them purified by fractional distillation and used immediately after purification.

The asymmetric Michael reactions of chiral imines, on its respective active nucleophile tautomers were summarized in the Scheme 4, and the ratio of diketones and respective de were presented in Table 1.

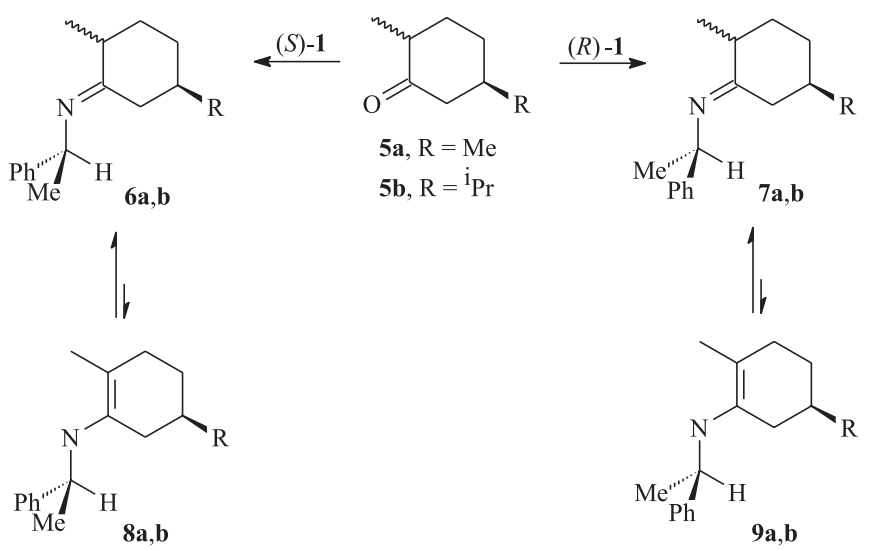

Scheme 1.

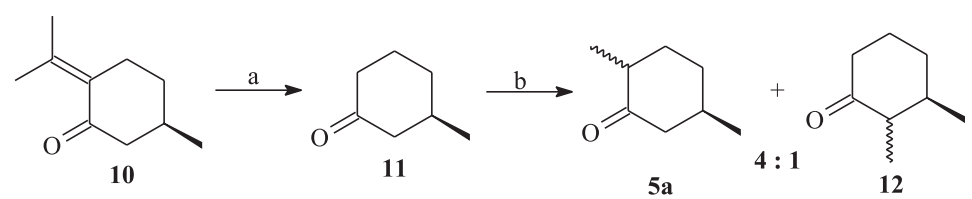

Scheme 2. Reagents and conditions: a) $\mathrm{HCl}_{\mathrm{aq}}$, reflux, $8 \mathrm{~h}, 70 \%$; b) $i$. LDA/LiBr, THF, $0{ }^{\circ} \mathrm{C}, 30 \mathrm{~min}$; ii. $\mathrm{MeI},-78{ }^{\circ} \mathrm{C}$ to $\mathrm{rt}, 85 \%$.
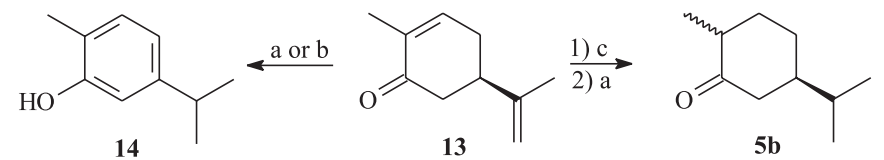

Scheme 3. Reagents and conditions: a) $\mathrm{H}_{2}$ (15 atm), $10 \% \mathrm{Pd} / \mathrm{C}$, EtOH, rt, 24h; b) limonene, $10 \% \mathrm{Pd} / \mathrm{C}$, reflux, 2h; c) Zn, KOH, EtOH, reflux, 2h, $85 \%$ (over two steps).

Table 1.

\begin{tabular}{|c|c|c|c|c|c|c|}
\hline Entry & enamine & PEA (1) & $\mathrm{R}-$ & Products $\left(\right.$ ratio $\left.^{a}\right)$ & Yield/(\%) & $\mathrm{de} /(\%)$ \\
\hline 1 & $8 \mathbf{a}$ & $S$ & Me- & 15a $\left(\right.$ only $\left.^{b}\right)$ & 69 & $>95$ \\
\hline 2 & $8 \mathbf{c}^{c}$ & $S$ & $-\mathrm{C}\left(\mathrm{CH}_{3}\right)=\mathrm{CH}_{2}$ & 15c $\left(\right.$ only $\left.^{b}\right)$ & $88^{c}$ & $>95^{c}$ \\
\hline 3 & $8 b$ & $S$ & ${ }^{i} \mathrm{Pr}-$ & $15 b+16 b(7.2: 1)$ & 60 & 76 \\
\hline 4 & $9 \mathbf{a}$ & $R$ & Me- & $\mathbf{1 5 a}+\mathbf{1 6 a}(1: 4.6)$ & 68 & 64 \\
\hline 5 & $9 \mathbf{c}^{c}$ & $R$ & $-\mathrm{C}\left(\mathrm{CH}_{3}\right)=\mathrm{CH}_{2}$ & $15 c+16 c(1: 3.8)$ & $88^{c}$ & $58^{c}$ \\
\hline 6 & 9b & $R$ & iPr- & $\mathbf{1 5 b}+\mathbf{1 6 b}(1: 2.3)$ & 56 & 39 \\
\hline
\end{tabular}

${ }^{a}$ Determined by GC; ${ }^{b}$ Diastereisomers $\mathbf{1 6 a}$ and/or $\mathbf{1 6 c}$ not detected in GC and ${ }^{13} \mathrm{C}$ NMR spectrum; ${ }^{c}$ Enamines $\mathbf{8 c}$ and $\mathbf{9 c}$ are respectively the tautomers of imines $\mathbf{6 c}$ and $\mathbf{7 c}$, prepared from (5R)-dihydrocarvone. ${ }^{8}$ 
The Michael reactions were performed in aprotic conditions (MVK, THF, 3 days) in standard procedure. ${ }^{8}$ As the epimeric diketones $\mathbf{1 5}$ and $\mathbf{1 6}$ cannot be separated, its ratio was determined by GC analysis. In order to establish its stereochemistry, they have been converted into octalones $\mathbf{1 7}$ and $\mathbf{1 9}$ among known ketols $\mathbf{1 8}$ and $\mathbf{2 0}^{32}$ as shown in Scheme 5, all of them purified and characterized by spectroscopic methods. ${ }^{8,32}$

Observing de results presented in Table 1 we can identify a clear influence of resident substituent in the enamine cycle onto the diastereoselectivity of Michael reaction. Using Houk' ${ }^{22}$ model we could rationalize the results, considering the conformational equilibrium of enamines 8a-c derived from $(S)$-1 shown in Scheme 6. Michael addition of all enamines presents large preference for $S i$ attack leading to products $\mathbf{1 5 a}-\mathbf{b}$ or $\mathbf{1 5 c}{ }^{8}$ Such attack is axially oriented only in the conformers $\mathbf{8} \mathbf{a}^{\prime}-\mathbf{c}$ ' in which $\mathrm{R}$ substituent has a pseudo-equatorial conformation. Furthermore these conformers are the most stable halfchair according Houk's statements if the absolute configuration of chiral auxiliary is $S$, when $\mathrm{R}=\mathrm{H} .{ }^{22}$ So, we can assume the stereoelectronic preference for an axial Si attack on conformers 8a'-c', explaining the experimental results. Increasing the size of $\mathrm{R}$ (Table 1 - Entry 3) leads to a disfavouring effect in conformer $\mathbf{8 b}$ ' $\left(\mathrm{R}={ }^{\mathrm{i}} \mathrm{Pr}\right)$ by non-ligand interactions of substituent with $\mathrm{S}^{*}$ and/or steric hindrance for $S i$ attack yielding a minoritary $R e$ attack product, probably via an axial attack in the highest energy conformer $\mathbf{8 b}$ " accounting to the lower $d e$ in this case.

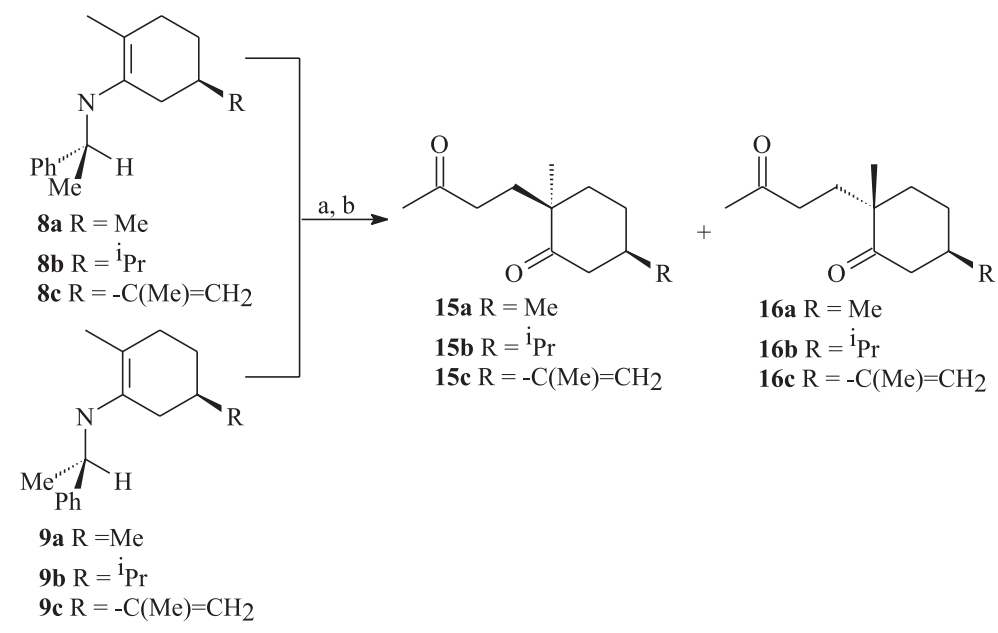

Scheme 4. Reagents and conditions: a) MVK, THF, rt, 3 days; b) $\mathrm{AcOH}_{\mathrm{aq}}$, rt, $1 \mathrm{~h}$.<smiles>CC(=O)CC[C@]1(C)CC[C@@H](C)CC1=O</smiles>

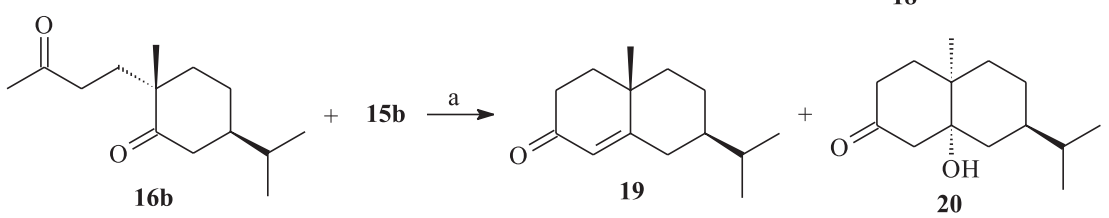

Scheme 5. Reagents and conditions: a) $\mathrm{KOH}, \mathrm{EtOH} / \mathrm{Et}_{2} \mathrm{O}, 0{ }^{\circ} \mathrm{C}, 1.5 \mathrm{~h}$.
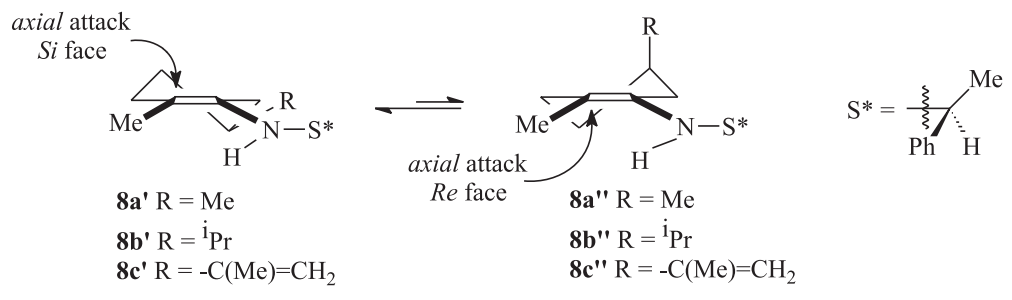

Scheme 6. 

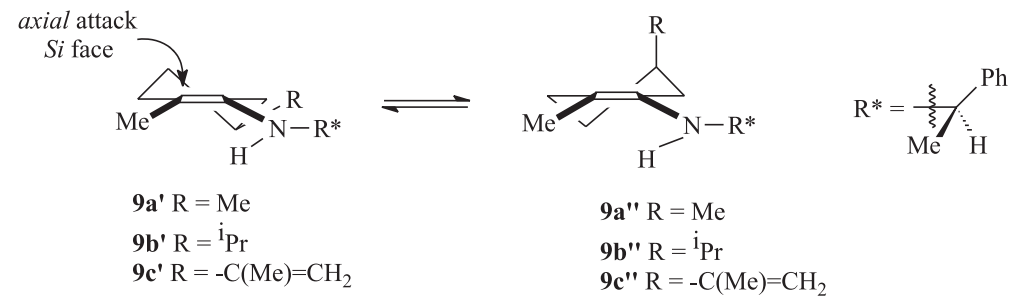

Scheme 7.

In contrast, Houk's model ${ }^{22}$ predicts conformers 9a"c" as the most stable in the conformational equilibrium of enamines $\mathbf{9 a}-\mathbf{b}$ or $9 \mathbf{c}^{8}$ derived from $(R)-\mathbf{1}$, but these conformers, as shown in Scheme 7 exhibit a pseudo-axial conformation for $\mathrm{R}$ substituent. Thus, we could imagine a compromise between two destabilizing factors: $i$ ) highenergy 1,3-diaxial interaction when $\mathrm{R}$ assumes a pseudoaxial conformation (conformers 9a"-c"); ii) non-ligand interactions between allylic hydrogens and atoms of chiral group (Houk's results) ${ }^{22}$ in conformers 9a'-c'.

If we assume Houk's postulate of stereoelectronic preference for axial attack, we could expect that products $\mathbf{1 5 a}-\mathbf{b}$ and $\mathbf{1 5} \mathbf{c}^{8}$ (minoritary ones) were formed by an axial $S i$-attack in conformers 9a'-c' while the majoritary products $\mathbf{1 6 a}-\mathbf{b}$ and $\mathbf{1 6} \mathbf{c}^{8}$ were originated from an axial $R e$ attack on conformers 9a"-c". Then, increasing $\mathrm{R}$ substituent size the equilibrium is shifted towards conformer (') lowering de, as we can observe in the order $\mathrm{R}=\mathrm{Me}$ to $\mathrm{R}=\mathrm{i} \operatorname{Pr}$ (entries 4 to 6 in Table 1). By the Curtin Hammett rule we can expect to obtain the products from the less stable conformers in the equilibrium if the kinetic barrier is smaller than the thermodynamic one. So, it will be necessary to calculate the energies of transition states for axial and equatorial attacks in both conformers shown in Scheme 7 to justify the preference for a $R e$ attack in this case.

The rationalization above proposes a kinetic control in the addition step, generally observed in the literature. In some cases thermodynamic control is observed via a reversible reaction, ${ }^{33}$ and more detailed study, experimental and theoretical are necessary to achieve definitive conclusions. These studies are in development at our laboratory.

\section{Conclusions}

The marked difference of diastereoselectivity between the two series of enamines can be associated to conformational factors during transition states in the alkylation step, in accordance to Houk's model. ${ }^{22}$ The results are consistent with a stereoelectronic control of the approach to the double bond of enamine. In the matched case, starting from $(S)$-PEA, the adducts are essentially derived from an axial $S i$ attack in the conformer $\mathbf{8} \mathbf{a}^{\prime}-\mathbf{b} \mathbf{b}^{\prime}$ or $\mathbf{8} \mathbf{c}^{\prime}{ }^{8}$ in all cases. These conformers present the substituent in a pseudoequatorial conformation and are the most stable according to Houk's model ${ }^{22}$ justifying high de obtained. In contrast with enamines prepared from $(R)$-PEA the most stable conformers predicted by Houk, ${ }^{22}$ have the substituent in a pseudoaxial conformation. There is a compromise between two destabilizing factors, lowering $d e$. However a relationship between diastereoselectivity and the size of R- is evident, the smallest substituent yields the larger selectivity. So we can conclude that the ability of enamine to reach conformers 9a"-b" or 9c" determines the possibility to $R e$ attack. By these considerations, we can associate the asymmetric induction of alkylation of chiral imines to a stereoelectronic control. The adducts could be formed even in axial attacks.

\section{Experimental}

General

${ }^{1} \mathrm{H}$ and ${ }^{13} \mathrm{C}$ NMR spectra were recorded on a Varian VXR-200 and signals are expressed downfield from the internal standard tetramethylsilane. Chemical shifts $(\delta)$ are reported in ppm and $\mathrm{CDCl}_{3}$ was used as solvent. Coupling constants $(J)$ are reported in Hertz $(\mathrm{Hz}) .{ }^{1} \mathrm{H}$ NMR data are reported in the following order: chemical shift, multiplicity (s, singlet; d, doublet; t, triplet; m, multiplet) and number of hydrogens. ${ }^{13} \mathrm{C}$ NMR spectra were interpreted with aid of APT and 2D correlation experiments. Infrared spectra were recorded with a Mattson Galaxy series FT-3000 spectrophotometer. Optical rotations were measured on a Perkin-Elmer 341 polarimeter at the sodium D line. Gas chromatography analyses were carried out with a Shimadzu GC-174 chromatograph with DB-1 column. Elemental analysis were performed in a Perkin-Elmer 2400 apparatus and melting points were determined with an Electrothermal IA 9000 series digital apparatus without temperature correction. All chemicals and solvents were of analytical grade and were used without further purification, with an 
exception of $(R)$-pulegone tech. grade purchased from Aldrich Chem. Co. and purified by column chromatography $\left([\alpha]_{D}+18.4^{\circ}\right.$, neat). THF was distilled from sodium/ benzophenone under argon immediately before use. Reactions were carried out under argon when necessary. Silica gel 60 F254 plates were used for TLC; 230-400 mesh silica gel was used for column chromatography.

\section{(3R)-3-methylcyclohexanone (11)}

$4.4 \mathrm{~g}(28.9 \mathrm{mmol})$ of $(R)$-pulegone (10) was added to a solution of $4.5 \mathrm{~mL}$ of concentred hydrochloric acid in $13.5 \mathrm{~mL}$ of water and the mixture was heated at reflux for $8 \mathrm{~h}$ and after a steam distillation the aqueous emulsion was extracted with ethyl ether $(3 \times 15 \mathrm{~mL})$. The ethereal layer was washed with brine and dried over anhydrous $\mathrm{MgSO}_{4}$, filtered off and the solvent was removed under reduced pressure. The crude material was purified by distillation in a Kugelrohr oven (bp $40-43^{\circ} \mathrm{C}$ at $2 \mathrm{mmHg}$ ) to give $2.3 \mathrm{~g}$ (20.5 mmol, 70\%) of $\mathbf{1 1}$ as a colorless oil, $[\alpha]_{D}+12.8^{\circ}$ (neat), $\left(\right.$ lit. $\left.^{25}+12.75^{\circ}\right)$.

\section{(5R)-2,5-dimethylcyclohexanone (5a)}

A solution of $1.37 \mathrm{~g}(12.2 \mathrm{mmol})$ of $(R)$-3-methylcyclohexanone (11) in $5 \mathrm{~mL}$ of dry THF was added dropwise at $-78{ }^{\circ} \mathrm{C}$ to a solution of LDA $(24.0 \mathrm{mmol})$ in $30 \mathrm{~mL}$ of THF containing $3.8 \mathrm{~g}$ (43.8 mmol) of $\mathrm{LiBr}$. The reaction was left for $45 \mathrm{~min}$ at $-78{ }^{\circ} \mathrm{C}$ then $4.7 \mathrm{~g}(33 \mathrm{mmol})$ of methyl iodide was added. After $1 \mathrm{~h}$ at $-78{ }^{\circ} \mathrm{C}$ and supplementary $1 \mathrm{~h}$ at room temperature the reaction was quenched with $5 \mathrm{~mL}$ of saturated aqueous $\mathrm{NH}_{4} \mathrm{Cl}$ and after extraction with ethyl ether $(3 \times 30 \mathrm{~mL})$ the organic layer was washed with brine and dried over anhydrous $\mathrm{MgSO}_{4}$, filtered off and the solvent was removed under reduced pressure. The crude material was purified by flash chromatography using hexane/ethyl acetate $8: 2$ as eluent yielding $1.3 \mathrm{~g}(10.4 \mathrm{mmol}, 85 \%)$ of a $4: 1$ mixture of inseparable regioisomers $5 \mathbf{a}$ cis and trans and of known $\mathbf{1 2}^{6}$ cis and trans, used without any further purification in the next step.

\section{Data for $5 a / 12$}

IR (neat) $v_{\max } / \mathrm{cm}^{-1}: 1709 .{ }^{1} \mathrm{H}$ NMR $\left(200 \mathrm{MHz}, \mathrm{CDCl}_{3}\right)$ $\delta$ 2.91-2.79 (m); 2.53-1.10 (m); 1.01-0.98 (m). 5a: ${ }^{13} \mathrm{C}$ NMR (50 MHz, $\left.\mathrm{CDCl}_{3}\right)$ : trans $\delta 213.9 ; 50.0 ; 44.4 ; 35.4$; $34.9 ; 31.0 ; 22.2 ; 14.2$. cis : $\delta 212.6 ; 47.3 ; 44.2 ; 33.9$; 32.6; 29.8; 19.6; 15.1. 12: $\left.{ }^{13} \mathrm{C} \mathrm{NMR} \mathrm{(50} \mathrm{MHz}, \mathrm{CDCl}_{3}\right)$ : trans : $\delta 212.8 ; 51.6 ; 41.3 ; 41.0 ; 34.1 ; 25.9 ; 20.5 ; 11.6$. cis: $\delta 212.6 ; 49.0 ; 40.5 ; 37.1 ; 33.9 ; 23.1 ; 21.8 ; 14.1$.

\section{(5R)-carvomenthone $(5 \mathrm{~b})$}

To a solution of $5.75 \mathrm{~g}(37.8 \mathrm{mmol})$ of $(5 R)$ dihydrocarvone $^{8}$ in $50 \mathrm{~mL}$ of ethanol was added $0.2 \mathrm{~g}$ of $10 \% \mathrm{Pd} / \mathrm{C}$. The mixture in a stainless steel reactor was submitted to $15 \mathrm{~atm}$ of $\mathrm{H}_{2}$ for $24 \mathrm{~h}$ under vigorous magnetic stirring. After filtration on a short column of silica gel the solvent was removed under reduced pressure leading to $5.6 \mathrm{~g}(36.3 \mathrm{mmol}, 96 \%)$ of $\mathbf{5 b}$ in a 7:1 mixture of trans and cis epimers as a colorless oil used without any further purification.

\section{Data for $\mathbf{5 b}$ trans and cis}

IR (neat) $v_{\max } / \mathrm{cm}^{-1}: 1713.1 \mathrm{H} \mathrm{NMR}\left(200 \mathrm{MHz}, \mathrm{CDCl}_{3}\right)$ $\delta$ 2.43-2.31 (m, 2H); 2.15-2.06 (m, 1H); 1.89-1.83 (m, $1 \mathrm{H})$; $1.61-1.12$ (m, 5H); 1.03 (d, 3H, J $6.4 \mathrm{~Hz}) ; 0.91$ (d, $3 \mathrm{H}, \mathrm{J} 6.5 \mathrm{~Hz}) ; 0.88$ (d, 3H, J $6.5 \mathrm{~Hz}) .{ }^{13} \mathrm{C} \mathrm{NMR}(50 \mathrm{MHz}$, $\left.\mathrm{CDCl}_{3}\right)$ trans $\delta 213.6 ; 46.5 ; 45.3 ; 44.9 ; 35.1 ; 32.7 ; 28.8$; $19.6 ; 19.3 ; 14.3$. cis $\delta 217.0 ; 44.7 ; 44.2 ; 42.9 ; 31.3 ; 30.6$; $25.1 ; 19.4 ; 19.3 ; 18.4$.

\section{General Procedure for the Michael reaction with chiral} imines

A mixture of $25 \mathrm{mmol}$ of 2-methyl-5-alkylcyclohexanone and $30 \mathrm{mmol}$ of PEA (1) and some crystals of p-TSA in $15 \mathrm{~mL}$ of benzene was refluxed for $4 \mathrm{~h}$ in a Dean-Stark apparatus with azeotropic removal of water. The end of reaction was determined by the disappearance of the carbonyl band around $1715 \mathrm{~cm}^{-1}$ in the IR spectrum. After removal of the solvent under reduced pressure the residue was distilled with a high-vacuum pump (residual amine bp $46-49^{\circ} \mathrm{C}$ and imine bp ranges from 110 to $140{ }^{\circ} \mathrm{C}$ at $0.01 \mathrm{~mm} \mathrm{Hg}$ ) to lead the chiral imine, immediately solved in $10 \mathrm{~mL}$ of dry THF. To this solution was added dropwise $2.0 \mathrm{~mL}(1.7 \mathrm{~g}$. $23 \mathrm{mmol})$ of MVK and the reaction is left at room temperature under inert atmosphere and magnetic stirring. After 3 days $10 \mathrm{~mL}$ of $10 \%$ aqueous $\mathrm{AcOH}$ was added and $1.5 \mathrm{~h}$ later the suspension was extracted with ethyl ether $(3 \times 15 \mathrm{~mL})$. The combined organic layers were washed with $5 \%$ aqueous $\mathrm{NaHCO}_{3}$ and brine, dried over anhydrous $\mathrm{MgSO}_{4}$, filtered off and concentred in rotatory evaporator. The corresponding diketones are purified by flash chromatography using variable hexane/ethyl acetate mixtures as eluent.

\section{Alkylation of imine $(\mathbf{6 a})$}

$3.4 \mathrm{~g}(26.9 \mathrm{mmol})$ of regioisomers $\mathbf{5 a} / \mathbf{1 2}$ and $3.66 \mathrm{~g}$ (30.2 mmol) of $(S)-1$ lead to $5.3 \mathrm{~g}(23.1 \mathrm{mmol}, 86 \%)$ of 
imine 6a (with by-product the imine derived from 12). After reaction with $2.1 \mathrm{~mL}(1.81 \mathrm{~g}, 25.8 \mathrm{mmol})$ of MVK and hydrolysis the crude material was purified by flash chromatography using hexane/ethyl acetate $85: 15$ as eluent yielding $3.1 \mathrm{~g}(5.8 \mathrm{mmol}, 69 \%)$ of diketone 15a as a colorless oil, then converted ${ }^{8}$ in the known ketol $18 .^{32}$

\section{Data for $15 a$}

IR (neat) $v_{\max } / \mathrm{cm}^{-1}: 1707 .{ }^{1} \mathrm{H} \mathrm{NMR}\left(200 \mathrm{MHz}, \mathrm{CDCl}_{3}\right)$ $\delta$ 2.58-2.05 (m, 4H); $2.13(\mathrm{~s}, 3 \mathrm{H}) ; 1.97-1.76$ $(\mathrm{m}, 2 \mathrm{H}) ; 1.74-1.40(\mathrm{~m}, 5 \mathrm{H}) ; 1.01$ (s, 3H); 0.99 (d, 3H, J $6.4 \mathrm{~Hz}) .{ }^{13} \mathrm{C}$ NMR $\left(50 \mathrm{MHz}, \mathrm{CDCl}_{3}\right) \delta 215.3 ; 208.8 ; 51.1$; $38.6 ; 38.5 ; 38.1 ; 29.7 ; 29.1 ; 28.8 ; 24.4 ; 18.5 ; 15.2$.

\section{Alkylation of imine (7a)}

$3.4 \mathrm{~g}(26.9 \mathrm{mmol})$ of regioisomers $\mathbf{5 a} / \mathbf{1 2}$ and $3.66 \mathrm{~g}$ (30.2 mmol) of $(R)-1$ lead to $5.0 \mathrm{~g}(21.8 \mathrm{mmol}, 81 \%)$ of imine $\mathbf{7 a}$ (with by-product the imine derived from 12 ). After reaction with $2.0 \mathrm{~mL}(1.71 \mathrm{~g}, 24.4 \mathrm{mmol})$ of MVK and hydrolysis was obtained a 4.6:1 mixture (GC) of inseparable epimeric diketones $\mathbf{1 6 a}$ and $\mathbf{1 5 a}$, purified by flash chromatography using hexane/ethyl acetate 85:15 as eluent yielding $2.9 \mathrm{~g}$ (14.78 mmol, 68\%) of combined products, used without any further purification in the next step.

\section{Obtainment of octalone (17) and ketol (18)}

$2.9 \mathrm{~g}(14.78 \mathrm{mmol})$ of a 4.6:1 mixture of diketones 16a/ 15a was added to a suspension of $0.7 \mathrm{~g} \mathrm{KOH}$ in $2.5 \mathrm{~mL}$ dry ethanol and $70 \mathrm{~mL}$ ethyl ether. After $1.5 \mathrm{~h}$ at $0{ }^{\circ} \mathrm{C}$ under inert atmosphere, the reaction was stopped by the addition of $5 \% \mathrm{NH}_{4} \mathrm{Cl}$ solution. The layers were separated and the ethereal extracts were washed with brine, dried over anhydrous $\mathrm{MgSO}_{4}$ and concentred under reduced pressure. The crude mixture was purified by flash chromatography. The fraction eluted with 3:1 hexane:ethyl ether afforded $1.29 \mathrm{~g}$ (7.24 mmol, 58\%) of octalone $\mathbf{1 7}$ as a pale yellow oil while elution with 1:1 hexane:ethyl ether lead to $0.30 \mathrm{~g}$ $(1.62 \mathrm{mmol}, 11 \%)$ of ketol $\mathbf{1 8},{ }^{32}$ as a white solid (mp 123$\left.125^{\circ} \mathrm{C}\right)$.

\section{Data for 17}

IR (neat) $v_{\max } / \mathrm{cm}^{-1}: 1674,1618 .{ }^{1} \mathrm{H}$ NMR $(200 \mathrm{MHz}$, $\left.\mathrm{CDCl}_{3}\right) \delta 5.74(\mathrm{~s}, 1 \mathrm{H}) ; 2.68-2.11(\mathrm{~m}, 4 \mathrm{H}) ; 2.09-1.75 \mathrm{~m}$, $6 \mathrm{H}) ; 1.68-1.35(\mathrm{~m}, 1 \mathrm{H}) ; 1.24(\mathrm{~s}, 3 \mathrm{H}) ; 0.89$ (d, 3H, J 6.3 $\mathrm{Hz}) .{ }^{13} \mathrm{C} \mathrm{NMR}\left(50 \mathrm{MHz}, \mathrm{CDCl}_{3}\right) \delta 199.5 ; 169.4 ; 126.2$; $38.9 ; 38.0 ; 35.9 ; 35.6 ; 34.1 ; 29.3 ; 27.3 ; 22.2 ; 17.9$. Calcd for $\mathrm{C}_{12} \mathrm{H}_{18} \mathrm{O}: \mathrm{C}, 80.85 ; \mathrm{H}, 10.18$. Found $\mathrm{C}, 81.02 ; \mathrm{H}, 10.33$.

\section{Data for 18}

IR $(\mathrm{KBr}) v_{\max } / \mathrm{cm}^{-1}: 3413,1708 .{ }^{1} \mathrm{H}$ NMR $(200 \mathrm{MHz}$, $\left.\mathrm{CDCl}_{3}\right) \delta 2.78(\mathrm{~d}, 1 \mathrm{H}, \mathrm{J} 13.7 \mathrm{~Hz}) ; 2.54$ (dt, 1H, J 13.1, 7.1 $\mathrm{Hz}$ ); 2.33 (m, 1H); 2.22 (d, 1H, J $13.7 \mathrm{~Hz}) ; 2.08$ (dt, 1H, J 13.2, $5.3 \mathrm{~Hz})$; 1.95-1.68 (m, 3H), 1.60-1.00 (m, 6H), 1.20 (s, 3H), 0.88 (d, 3H, J $6.4 \mathrm{~Hz}) .{ }^{13} \mathrm{C} \mathrm{NMR}(50 \mathrm{MHz}$, $\left.\mathrm{CDCl}_{3}\right) \delta 210.0 ; 75.5 ; 53,2 ; 43.5 ; 37.6 ; 36.6 ; 34.8 ; 31.7$; $29.5 ; 27.8 ; 22.0 ; 21.7$.

\section{Alkylation of imine (6b)}

$3.8 \mathrm{~g}(24.6 \mathrm{mmol})$ of $(5 R)$-carvomenthone $(\mathbf{5 b})$ and 3.36 $\mathrm{g}(27.7 \mathrm{mmol})$ of $(S)-1$ lead to $5.5 \mathrm{~g}(21.4 \mathrm{mmol}, 87 \%)$ of imine 6b. After reaction with $2.1 \mathrm{~mL}(1.83 \mathrm{~g}, 26.1 \mathrm{mmol})$ of MVK and hydrolysis was obtained a 7.2:1 mixture (GC) of inseparable epimeric diketones $\mathbf{1 5 b}$ and $\mathbf{1 6 b}$, purified by flash chromatography using hexane/ethyl acetate 8:2 as eluent yielding $2.9 \mathrm{~g}$ (12.93 mmol, 60\%) of combined products, used without any further purification in the next step.

\section{Alkylation of imine (7b)}

$3.8 \mathrm{~g}(24.6 \mathrm{mmol})$ of $(5 R)$-carvomenthone $(\mathbf{5 b})$ and 3.36 $\mathrm{g}(27.7 \mathrm{mmol})$ of $(R)-1$ lead to $5.2 \mathrm{~g}(20.2 \mathrm{mmol}, 82 \%)$ of imine 7b. After reaction with $2.0 \mathrm{~mL}(1.71 \mathrm{~g}, 24.4 \mathrm{mmol})$ of MVK and hydrolysis was obtained a 2.3:1 mixture (GC) of inseparable epimeric diketones $\mathbf{1 6 b}$ and $\mathbf{1 5 b}$, purified by flash chromatography using hexane/ethyl acetate 8:2 as eluent yielding $2.7 \mathrm{~g}$ (12.03 mmol, 56\%) of combined products, used without any further purification in the next step.

\section{Obtainment of octalone (19) and ketol (20)}

To a solution of $4.25 \mathrm{~g}(18.9 \mathrm{mmol})$ diketones $\mathbf{1 5 b} / \mathbf{1 6 b}$ (7.2:1) in $50 \mathrm{~mL}$ ethyl ether was added $2.5 \mathrm{~mL}$ solution ethanolic $\mathrm{KOH} 2.9 \mathrm{~mol} \mathrm{~L}-1$. After $1.5 \mathrm{~h}$ at $0{ }^{\circ} \mathrm{C}$ under inert atmosphere, the layers were separated and the ethereal extracts were washed with brine, dried over anhydrous $\mathrm{MgSO}_{4}$ and concentred under reduced pressure. The crude mixture was purified by flash chromatography. The fraction eluted with 3:1 hexane:ethyl ether afforded $0.45 \mathrm{~g}(2.3$ mmol, $12 \%$ ) of a pale yellow oil octalone 19 while elution with 1:1 hexane:ethyl ether lead to $2.84 \mathrm{~g}(12.9 \mathrm{mmol}, 68 \%)$ of known ketol 20, ${ }^{32}$ as a white solid (mp 139-141 ${ }^{\circ} \mathrm{C}$ ).

\section{Data for 19}

IR (neat) $v_{\max } / \mathrm{cm}^{-1}: 1678,1623 .{ }^{1} \mathrm{H}$ NMR $(200 \mathrm{MHz}$, $\left.\mathrm{CDCl}_{3}\right) \delta 5.73(\mathrm{~s}, 1 \mathrm{H}) ; 2.60-2.01(\mathrm{~m}, 4 \mathrm{H}) ; 1.83-1.69(\mathrm{~m}$, $4 \mathrm{H}) ; 1.41-1.25(\mathrm{~m}, 3 \mathrm{H}) ; 1.21(\mathrm{~s}, 3 \mathrm{H}) ; 0.91(\mathrm{~d}, 6 \mathrm{H}, J 6.7$ 
$\mathrm{Hz}) .{ }^{13} \mathrm{C}$ NMR $\left(50 \mathrm{MHz}, \mathrm{CDCl}_{3}\right) \delta 199.7 ; 171.0 ; 124.2$; $45.3 ; 41.3 ; 37.8 ; 36.4 ; 35.7 ; 33.9 ; 32.6 ; 24.8 ; 22.0 ; 19.6$; 19.4. Calc. for $\mathrm{C}_{14} \mathrm{H}_{22} \mathrm{O}: \mathrm{C}, 81.50 ; \mathrm{H}, 10.75$. Found C, 81.68; H, 10.92.

\section{Data for 20}

IR (KBr) $v_{\max } / \mathrm{cm}^{-1}: 3536,1701 .{ }^{1} \mathrm{H}$ NMR $(200 \mathrm{MHz}$, $\left.\mathrm{CDCl}_{3}\right) \delta 3.01(\mathrm{~d}, 1 \mathrm{H}, J 13.5 \mathrm{~Hz}) ; 2.10-2.08(\mathrm{~m}, 3 \mathrm{H})$; 1.68-1.61 (m, 4H); 1.49-1.33 (m, 6H); 1.04 (s, 3H); 0.90 $(\mathrm{d}, 6 \mathrm{H}, J 6.8 \mathrm{~Hz}) .{ }^{13} \mathrm{C} \mathrm{NMR}\left(50 \mathrm{MHz}, \mathrm{CDCl}_{3}\right)$ $\delta 209.7 ; 75.5 ; 53,3 ; 38.8 ; 38.5 ; 37.6 ; 36.8 ; 34.7 ; 32.3$; $31.6 ; 23.8 ; 21.7 ; 19.8 ; 19.6$.

\section{Acknowledgments}

The authors are grateful to CNPq and CAPES, Brazilian agencies for fellowships to M. M. Victor and E. M. dos Santos, to Propesq/UFRGS for University grant to M. Bogdan and FAPERGS, state agency and CNPq for research funds.

\section{References}

1. Pfau, M.; Revial, G.; Guingant, A.; d'Angelo, J.; J. Am. Chem. Soc. 1985, 107, 273.

2. d'Angelo, J.; Desmaële, D.; Dumas, F.; Guingant, A.; Tetrahedron: Asymmetry 1992, 3, 459.

3. d'Angelo, J.; Cave, C.; Desmaële, D.; Dumas, F. In Trends in Organic Chemistry; Pandalai, S. G., ed., Trivandrum: India, 1993.

4. Thominiaux, C.; Rousse, S.; Desmaële, D.; d'Angelo, J.; Riche, C.; Tetrahedron: Asymmetry 1999, 10, 2015.

5. Pinheiro, S.; Guingant, A.; Desmaële, D.; d'Angelo, J.; Tetrahedron: Asymmetry 1992, 3, 1003.

6. Schenato, R. A.; dos Santos, E. M.; Tenius, B. S. M.; Costa, P. R. R.; Caracelli, I.; Zukerman-Schpector, J.; Tetrahedron: Asymmetry 2001, 12, 579.

7. Tori, M.; Hisazumi, K.; Wada, T.; Sono, M.; Nakashima, K.; Tetrahedron: Asymmetry 1999, 10, 961.

8. Tenius, B. S. M.; de Oliveira, E. R.; Ferraz, H. M. C.; Tetrahedron: Asymmetry 1993, 4, 633.

9. Revial, G.; Tetrahedron Lett. 1989, 30, 4121.

10. Witschel, M. C.; Bestmann, H. J.; Synthesis 1997, 107.

11. Agami, C.; Kadouri-Puchot, C.; Le Guen, V.; Tetrahedron: Asymmetry 1993, 4, 641; Haaksma, A. A.; Jansen, B. J. M.; de Groot, A.; Tetrahedron 1992, 48, 3121; Ho, T. L.; Enantioselective Syntheses. Natural Products from Chiral Terpenes; John Wiley: New York, 1992; and references cited therein.
12. Tenius, B. S. M.; Rohde, A. R.; Victor, M. M.; Viegas, Jr., C.; Synth. Commun. 1996, 26, 197.

13. Xiong, Z. M.; Yang, J.; Li, Y. L.; Tetrahedron: Asymmetry 1996, 7, 2607

14. Chen, Y. G.; Zhou, G.; Liu, L. J.; Xiong, Z. M.; Li, Y. L.; Synthesis 2001, 1305.

15. Chen, Y. G.; Xiong, Z. M.; Zhou, G.; Liu, L. J.; Li, Y. L.; Tetrahedron: Asymmetry 1998, 9, 1923.

16. Zhang, Z.; Xiong, Z. M.; Zheng, G. J.; Li, Y. L.; Tetrahedron: Asymmetry 2001, 12, 2137; Gao, X. L.; Xiong, Z. M.; Zhou, G.; Li, Y. L.; Synthesis 2001, 37; Zhou, G.; Gao, X. L.; Zhang, Z.; Li, W. D. Z.; Li, Y. L.; Tetrahedron: Asymmetry 2000, 11, 1819; Zhou, G.; Gao, X. L.; Zhang, Z.; Li, Y. L.; J. Chem. Res. (S) 2000, 174; Zhou, G.; Xiong, Z. M.; Chen, Y. G.; Li, Y. L.; J. Chem. Res. (S) 1998, 650; Xiong, Z. M.; Zhou, G.; Chen, Y. G.; Li, Y. L.; J. Chem. Res. (S) 1998, 450; Chen, Y. G.; Xiong, Z. M.; Zhou, G.; Yang, J.; Li, Y. L.; Chem. Lett. 1997, 1289.

17. Zhabinskii, V. N.; Minnaard, A. J.; Wijnberg, J. B. P. A.; de Groot, A.; J. Org. Chem. 1996, 61, 4022.

18. Sevin, A.; Tortajada, J.; Pfau, M.; J. Org. Chem. 1986, 51, 2671.

19. Sevin, A.; Masure, D.; Giessner-Prettre, C.; Pfau, M.; Helv. Chim. Acta 1990, 73, 552.

20. Tran-Huu-Dau, M. E.; Riche, C.; Dumas, F.; d'Angelo, J.; Tetrahedron: Asymmetry 1998, 9, 1059.

21. d'Angelo, J.; Revial, G.; Guingant, A.; Riche, C.; Chiaroni, A.; Tetrahedron Lett. 1989, 30, 2645.

22. Lucero, M. J.; Houk, K. N.; J. Am. Chem. Soc. 1997, 119, 826.

23. Evans, D. In Asymmetric Synthesis; Morrison, J. D., ed., Academic Press: Orlando, 1984, vol. 3.

24, Schenato, R. A.; dos Santos, E. M.; Tenius, B. S. M.; de Oliveira, E. R.; Quim. Nova 2003, 26, 717.

25. Djerassi, C.; Krakower, G. W.; J. Am. Chem. Soc. 1959, 81, 237.

26. Jackman, L. M.; Dunne, T. S.; J. Am. Chem. Soc. 1985, 107, 2805.

27. Molander, G. A.; Haas, J.; Tetrahedron 1999, 55, 617.

28. Revial, G.; Jabin, I.; Pfau, M.; Tetrahedron: Asymmetry 2000, 11, 4975.

29. Takaki, K.; Okada, M.; Yamada, M.; Negoro, K.; J. Org. Chem. 1982, 47, 1200.

30. Brieger, G.; Nestrick, T. J.; Chem. Rev. 1974, 74, 567.

31. von Holleben, M. L. A.; Zucolotto, M.; Zini, C. A.; de Oliveira, E. R.; Tetrahedron 1994, 50, 973.

32. Schenato, R. A.; dos Santos, E. M.; Gonçalves, P. F. B.; Tenius, B. S. M.; de Oliveira, E. R.; Caracelli, I.; Zukerman-Schpector, J.; Magn. Reson. Chem. 2003, 41, 53.

33. Pizzonero, M.; Hendra, F.; Delarue-Cochin, S.; Tran-Huu-Dau, M. E.; Dumas, F.; Cave, C.; Nour, M.; d'Angelo, J.; Tetrahedron: Asymmetry 2005, 16, 3853.

Received: June 30, 2006 Web Release Date: March 23, 2007 